\title{
The Simulation Study of Multicycle Injection-production of the Underground Gas Storage in the High Water Cut Reservoir
}

\author{
Jin Chang, Shusheng Gao, Ke Xu \\ Institute of Porous flow \& Fluid Mechanics, \\ CNPC \& UCAS, \\ Langfang, 065007, China
}

\begin{abstract}
It is unavoidable of the complex coexistence of gas, water and oil phase in the underground gas storage which is built after the late water flooding of the high water cut sandstone reservoir. This paper does experiments of setting and unsetting pressure of multicycle injection-production experiment using plane visual glass model. The process of the gas operation can be seen intuitively of the anticline structure model, plane homogeneous model and plane heterogeneity model. Moreover, two main influence factors for the efficiency of the gas operation are concluded. The result shows: the capacity of the gas storage and the efficiency of the gas operation are tend to be stable after multicycle injection-production. The efficiency of the gas operation has a closely relationship with reservoir geological features and injection pressure. The conclusion has guiding roles for building and operating underground gas storage of high water cut sandstone reservoir.
\end{abstract}

Keywords-high water cut reservoir; multicycle injection-production; the efficiency of the gas operation; reservoir geological features; injection pressure

\section{INTRODUCTION}

Utilizing underground aquifer in depleted oilfields to build underground gas storage is one of the most main technological achievements in the 20th century. One of the main technical problems to solve the gas storage building is how to improve the efficiency of macroscopic and microscopic sweep of gas drive[1-2].Most scientists use the numerical simulation [3-4] and gas drive physical simulation to do research on the multicycle injection-production. But the numerical simulation can't reflect the actual operation mode due to it's idealized. Besides, the artificial core[5] and micro etching model[6-7] which different from the actual reservoir are always used in physical simulation and they can't be seen intuitively of the seepage law of gas, water and oil in the internal of the reservoir.

Plane visual glass model is used in the experiment of multicycle gas-water drive and visually observed the distribution of gas, water and oil in different model. In addition, the study of the factors which influence the efficiency of gas operation are complicated to put forward the opinions and suggestions to actual underground gas storage.

\section{DEVICE AND MATERIALS}

Figure 1 shows the device of this experiment including displacement equipment, observation equipment, gathering equipment and metering equipment.

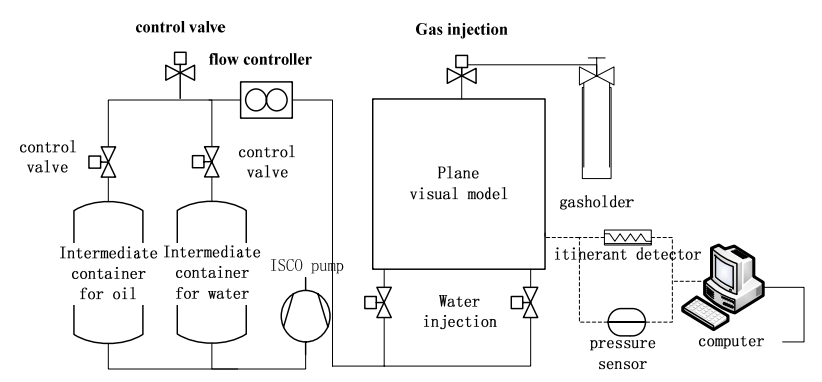

Figure 1. Physical simulation device schematic diagram

Firstly, make the model saturated oil. Secondly, displace oil by water until the model in the state of high water cut. Thirdly, calculate the saturation of gas, water and oil after every gas injection-production.

The gas, water and oil which inject are $\mathrm{CO}_{2}$, $\mathrm{Na}_{2} \mathrm{CO}_{3}$-phenolphthalein and kerosene. The color of $\mathrm{Na}_{2} \mathrm{CO}_{3}$-phenolphthalein when meet with $\mathrm{CO}_{2}$ will change from pink to white. Using this method can observe the displacement front and regularities of distribution of gas and water drive more intuitively.

$$
\mathrm{Na}_{2} \mathrm{CO}_{3}+\mathrm{CO}_{2}+\mathrm{H}_{2} \mathrm{O} \rightarrow 2 \mathrm{NaHCO}_{3}
$$

\section{MULTICYCLE INJECTION-PRODUCTION OF SETTING PRESSURE OF VISUAL MODEL}

\section{A. Multicycle gas operation of plane heterogeneity anticline structure model}

Plane heterogeneity anticline structure model (anticline model for short) is filled with 40 mesh quartz sand in the middle as the anticline structure, and 200 mesh quartz sand around as the mudstone layer of a reservoir. Figure 2 shows the intermediate process of the gas drive and water drive. It can be seen that the path are similar which all precursor along the anticline structure. So the anticline structure of high permeability is the main reservoir space and flow channels and the pore volume size determines the capacity of the gas operation. 


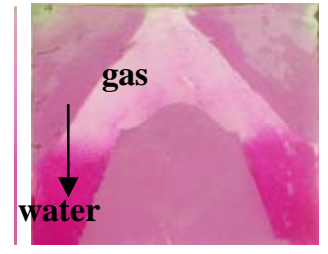

gas

Figure 2. The process of gas and water drive of anticline model

TABLE I. THE FIVE TIMES OF GAS INJECTION RESULT OF ANTICLINE MODEL (\%)

\begin{tabular}{ccccccc}
\hline Saturation & Initial & First & Second & Third & Forth & Fifth \\
\hline $\mathrm{S}_{\mathrm{g}}$ & 0 & 40.2 & 35.7 & 32.2 & 32.2 & 32.2 \\
$\mathrm{~S}_{\mathrm{w}}$ & 83.2 & 43.0 & 47.5 & 51.0 & 51.0 & 51.0 \\
$\mathrm{~S}_{\mathrm{o}}$ & 16.8 & 16.8 & 16.8 & 16.8 & 16.8 & 16.8 \\
& & & & & & \\
\hline
\end{tabular}

TABLE II. THE FIVE TIMES OF GAS PRODUCTION RESULT OF ANTICLINE MODEL (\%)

\begin{tabular}{ccccccc}
\hline Saturation & Initial & First & Second & Third & Forth & Fifth \\
\hline $\mathrm{S}_{\mathrm{g}}$ & 0 & 1.8 & 0.6 & 0 & 0 & 0 \\
$\mathrm{~S}_{\mathrm{w}}$ & 0 & 81.4 & 82.6 & 83.2 & 83.2 & 83.2 \\
$\mathrm{~S}_{\mathrm{o}}$ & 0 & 16.8 & 16.8 & 16.8 & 16.8 & 16.8 \\
\hline
\end{tabular}

The gas, water and oil saturation after five injection-production are showed as followings (Table I\&II). According to the statistics, the gas saturation down to $32.2 \%$ after multicycle gas drive and the water saturation remained above $80 \%$ after multicycle water drive. Besides, the oil saturation is keep to $16.8 \%$ with no change. It illustrates that the capacity of gas storage and the efficiency of gas operation are tend to be stable.

\section{B. Multicycle gas operation of plane homogeneous model}

Plane homogeneous model (homogeneous model for short) is filled with 120 mesh quartz sand. Figure 3 shows the intermediate process of the gas drive and water drive. It can be seen that the path are similar which from dispersed to gathered as a spindle type because of the characteristic of homogeneous. All the homogeneous part is the gas storage space and the pore volume size determines the capacity of the gas operation.

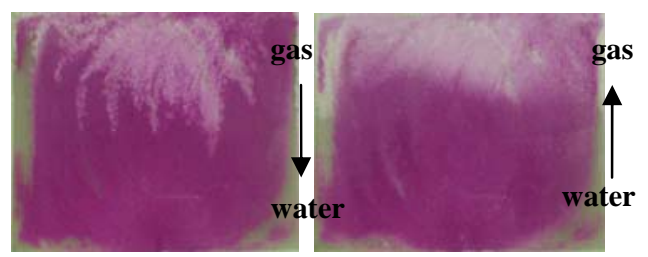

Figure 3. The process of gas and water drive of homogeneous model
TABLE III. THE FIVE TIMES OF GAS INJECTION RESULT OF HOMOGENEOUS MODEL $(\%)$

\begin{tabular}{cccllll}
\hline Saturation & Initial & First & Second & Third & Forth & Fifth \\
\hline $\mathrm{S}_{\mathrm{g}}$ & 0 & 36.3 & 32.1 & 29.2 & 29.2 & 29.2 \\
$\mathrm{~S}_{\mathrm{w}}$ & 74.6 & 38.3 & 42.5 & 45.4 & 45.4 & 45.4 \\
$\mathrm{~S}_{\mathrm{o}}$ & 25.4 & 25.4 & 25.4 & 25.4 & 25.4 & 25.4 \\
\hline
\end{tabular}

TABLE IV. THE FIVE TIMES OF GAS PRODUCTION RESULT OF HOMOGENEOUS MODEL (\%)

\begin{tabular}{ccllcrc}
\hline Saturation & Initial & First & Second & Third & Forth & Fifth \\
\hline $\mathrm{S}_{\mathrm{g}}$ & 0 & 9.4 & 9.1 & 8.3 & 8.3 & 8.3 \\
$\mathrm{~S}_{\mathrm{w}}$ & 0 & 64.9 & 65.5 & 66.3 & 66.3 & 66.3 \\
$\mathrm{~S}_{\mathrm{o}}$ & 0 & 25.4 & 25.4 & 25.4 & 25.4 & 25.4 \\
\hline
\end{tabular}

The gas, water and oil saturation after five injection-production are showed as followings (Table III\&IV). According to the statistics, the gas saturation down to $29.2 \%$ after multicycle gas drive and the water saturation remained above $66 \%$ after multicycle water drive. Besides, the oil saturation is keep to $25.4 \%$ with no change. It illustrates that the capacity of gas storage and the efficiency of gas operation are tends to be stable.

\section{Multicycle gas operation of plane heterogeneity composite rhythms model}

Plane heterogeneity composite rhythms model (heterogeneity model for short) is filled with 40 mesh quartz sand in the up and down two layers, and 120 mesh quartz sand in the middle. Figure 4 shows the intermediate process of the gas drive and water drive. It can be seen that the path are similar which are all spread from the periphery to the inside gradually due to the two water wells in the left and right angle. The main gas storage space is upper high permeability layer and the pore volume size determines the capacity of the gas operation.
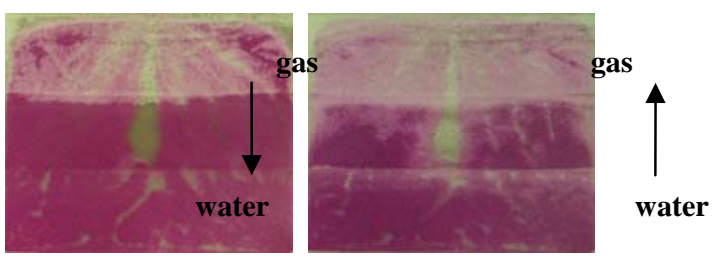

Figure 4. The process of gas and water drive of heterogeneity model

TABLE V. THE FIVE TIMES OF GAS INJECTION RESULT OF HETEROGENEITY MODEL (\%)

\begin{tabular}{cccllll}
\hline Saturation & Initial & First & Second & Third & Forth & Fifth \\
\hline $\mathrm{S}_{\mathrm{g}}$ & 0 & 31.9 & 26.3 & 25.7 & 25.7 & 25.7 \\
$\mathrm{~S}_{\mathrm{w}}$ & 70.6 & 38.7 & 44.3 & 44.9 & 44.9 & 44.9 \\
$\mathrm{~S}_{\mathrm{o}}$ & 29.4 & 29.4 & 29.4 & 29.4 & 29.4 & 29.4 \\
\hline
\end{tabular}


TABLE VI. THE FIVE TIMES OF GAS PRODUCTION RESULT OF HETEROGENEITY MODEL (\%)

\begin{tabular}{ccccccc}
\hline Saturation & Initial & First & Second & Third & Forth & Fifth \\
\hline $\mathrm{S}_{\mathrm{g}}$ & 0 & 10.4 & 12.2 & 13.8 & 13.8 & 13.8 \\
$\mathrm{~S}_{\mathrm{w}}$ & 0 & 60.2 & 58.4 & 56.8 & 56.8 & 56.8 \\
$\mathrm{~S}_{\mathrm{o}}$ & 0 & 29.4 & 29.4 & 29.4 & 29.4 & 29.4 \\
\hline
\end{tabular}

The gas, water and oil saturation after five injection-production are showed as followings (Table V\&VI). According to statistics, the gas saturation down to $25.7 \%$ after multicycle gas drive and the water saturation remained above $56.8 \%$ after multicycle water drive. Besides, the oil saturation is keep to $29.4 \%$ with no change. It illustrate that the capacity and the efficiency of gas storage are tends to be stable.

\section{The comparison of the efficiency of gas operation}

Figure 5 shows the comparison about the efficiency of the gas operation that indicates the anticline model is the first, the homogeneous model is the second and the heterogeneity model is the last. The gas recovery tends to be stable and the flow range has been confirmed after multicycle gas injection-production. The better of the heterogeneity, the higher of the permeability and initial water saturation are all benefit to the efficiency of the gas storage. Anticline model has more advantages because the tensile stress in the anticline axis structure showed the strongest[8]. So it is better to choose a high water anticline reservoir which is homogeneous and high permeability when in actual field.

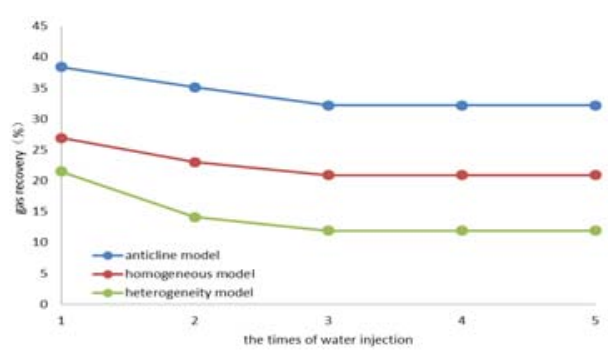

Figure 5. The comparison of the efficiency of the gas operation of three models

\section{MULTICYCLE INJECTION-PRODUCTION OF UNSETTING PRESSURE OF VISUAL MODEL}

This paper also studies the relationship between injection pressure[9] and gas saturation in the multicycle injection-production (Table VII\&VIII\&IX). For the first gas injection, improving injection pressure can increase the efficiency of gas operation effectively and expand the capacity of the gas storage. But increasing injection pressure has little to do in the subsequent experiments. It can be concluded that the storage capacity is gradually stabilized after multicycle injection-production.

For the homogeneous model and heterogeneity model, the late four times of experiments can also improve the efficiency of the gas storage up to $9 \%$ effectively. But for the anticline model, it has little function. Because of the bigger permeability differential of the anticline reservoir, improving gas injection pressure has less affected with the operation efficiency. So in actual field, improving injection pressure appropriately can increase the efficiency of the gas operation due to different reservoir geological features especially the first injection.

TABLE VII. THE EFFICIENCY OF UNSETTING INJECTION PRESSURE OF ANTICLINE MODEl $(\%)$

\begin{tabular}{cccccc}
\hline Injection pressure & First & $\begin{array}{c}\text { Secon } \\
\mathrm{d}\end{array}$ & Third & Forth & Fifth \\
\hline $0.02 \mathrm{~atm}$ & 39.3 & 38.4 & 39.2 & 39.1 & 39.1 \\
$0.05 \mathrm{~atm}$ & 52.2 & 39.5 & 41.1 & 41.7 & 40.1 \\
Added value & 12.9 & 1.1 & 1.9 & 2.6 & 1 \\
\hline
\end{tabular}

TABLE VIII. THE EFFICIENCY OF UNSETTING INJECTION PRESSURE OF HOMOGENEOUS MODEL(\%)

\begin{tabular}{cccccc}
\hline Injection pressure & First & $\begin{array}{c}\text { Secon } \\
\mathrm{d}\end{array}$ & Third & Forth & Fifth \\
\hline $0.02 \mathrm{~atm}$ & 31.9 & 27.2 & 28.7 & 26.9 & 23.3 \\
$0.05 \mathrm{~atm}$ & 48.6 & 35.3 & 31.4 & 31.4 & 32.3 \\
Added value & 16.7 & 8.1 & 2.7 & 4.5 & 9 \\
\hline
\end{tabular}

TABLE IX. THE EFFICIENCY OF UNSETTING INJECTION PRESSURE OF HETEROGENEITY MODEL $(\%)$

\begin{tabular}{cccccc}
\hline Injection pressure & First & $\begin{array}{c}\text { Secon } \\
\mathrm{d}\end{array}$ & Third & Forth & Fifth \\
\hline 0.02atm & 19.8 & 23.1 & 25.7 & 21.9 & 25.6 \\
0.05atm & 41.1 & 31.6 & 32.8 & 30.9 & 29.9 \\
Added value & 21.3 & 8.5 & 7.1 & 9 & 4.3 \\
\hline
\end{tabular}

\section{CONCLUSION}

(1) The pore space, occupied by water flooding seepage channel, is the main gas storage space and the size determines the capacity of injection-production. The path of gas drive and water drive are roughly the same. Besides, the capacity of the gas storage and efficiency of the gas operation tend to be stable after multicycle injection-production.

(2) The efficiency of gas operation is closely related to reservoir geological features. The better of the reservoir homogeneity, the higher of the permeability and initial water saturation are all benefit to the efficiency of gas operation. Moreover, anticline structure has more advantages for reserving and operating gas.

(3) The efficiency of gas operation is closely related to injection pressure. In actual field, improving injection pressure appropriately can increase the efficiency of the gas operation especially the first injection. But for the anticline reservoir whose permeability differential is bigger, improving injection pressure has little influence on gas operation. 


\section{REFERENCES}

[1] Jieming Wang, et al. The physical simulation study on the gas-drive multiphase flow mechanism of aquifer gas storage[J]. Natural Gas Geoscience. 17(4),pp. 597-600, 2006.

[2] Fansheng Ban, Shusheng Gao, Jieming Wang. Gas Injection-production Mechanism of Gas Storage in Depleted Oil Reservoirs[J]. Natural Gas Geoscience. 20(6),pp.1006-1008,2009.

[3] Huimeng Wang. The research on injection-production capability of the gas storage [D]. China University of Petroleum. 2011

[4] Shunpeng Zeng. The percolation mechanism and application research of gas storage rebuilding by the late high water cut reservoir [D]. Southwest Petroleum Institute. 2005

[5] Daoyong Zhou. The research of gas storage rebuilt by the late high water cut reservoir and Water-bearing structure[D]. Southwest Petroleum University. 2006
[6] Billiotte J.A., De Moegen H., Oren P., Experimental micromodeling and numerical simulation of gas water injection withdrawal as applied to underground gas storage[A].SPE20765.1993

[7] Sohrabi M., et al,visualization of oil recovery by water-alternation-gas injection using high-pressure micromodels. SPE89000.2004

[8] Denglin Han, Zhong Li, Jianfeng Show. Reservoir property difference between structural positions in the anticline: A case study from Kela-2 gas field in the Kuqa Depression, Tarim Basin, NW China[J]. Petroleum Exploration and Development. 38(3),pp.282-286, 2011.

[9] Yuhong Du, Miao Li, Jianfen Du, et al. Experiment study on injection-production rate sensibility of reconstructing underground natural gas storage[J]. Journal of Southwest Petroleum University. 29(2), pp.27-30. 2007, 